\title{
Dramatic reduction in predation on marine turtle nests through improved predator monitoring and management
}

\author{
Richard M. Engeman, R. Erik Martin, Henry T. Smith, John Woolard, Carrie K. Crady, Stephanie A. Shwiff, \\ Bernice Constantin, Margo Stahl and John Griner
}

\begin{abstract}
We describe improvements to monitoring/ indexing methodology for predators of marine turtle nests on the east coast of Florida, and the resulting marine turtle conservation implications from integrating the methodology into predator management. A strip transect from dune line to the shore improved an already successful design for monitoring raccoons, and was also sensitive for armadillos. The data were integrated into predator management operations to effectively and efficiently remove the species responsible for turtle nest predation. Tracking plot data also served to validate predator patterns of behavior relative to turtle nesting and improve prospects for preventive predator
\end{abstract}

management strategies. Perhaps the most important finding is that predation at a beach historically suffering nearly complete losses (95\%) of marine turtle nests had nest predation reduced to nominal levels (9.4\%). For 2002 this predation level represents an estimated 69,000 additional hatchling turtles produced over historical predation rates, and 16,700 additional hatchlings over the previous lowest predation rate.

Keywords Armadillo, endangered species, Florida, marine turtle, population index, predator management, raccoon.

\section{Introduction}

Marine turtle nesting beaches in Florida have been substantially altered by urbanization and development. Raccoons Procyon lotor are abundant native animals that affect marine turtle conservation at most Florida beaches through nest depredation (Stancyk, 1982; Williams-Walls et al., 1983). Raccoons flourish in association with humans, receiving artificial support through refuse or direct feeding (Dickman \& Doncaster, 1987; Riley et al., 1998; Smith \& Engeman, 2002). Florida also has one of the two most severe invasive species problems in the

Richard M. Engeman (Corresponding author) and Stephanie A. Shwiff National Wildlife Research Center, 4101 LaPorte Ave, Fort Collins, CO 80521-2154, USA. E-mail richard.m.engeman@aphis.usda.gov

R. Erik Martin and Carrie K. Crady Ecological Associates, Inc., P.O. Box 405, Jensen Beach, FL 34958, USA.

Henry T. Smith Florida Department of Environmental Protection, Florida Park Service, 13798 S.E. Federal Highway, Hobe Sound, FL 33455, USA.

John Woolard and Bernice Constantin USDA/APHIS/Wildlife Services, 2820 East University Ave., Gainesville, FL 32641, USA

Margo Stahl Hobe Sound NWR, 13640 S.E. Federal Hwy, Hobe Sound, FL 33455, USA

John Griner St. Lucie Inlet Preserve State Park, 16450 S.E. Federal Highway, Hobe Sound, FL 33455, USA.

Received 15 April 2004. Revision requested 19 October 2004 Accepted 17 December 2004.
United States (US Congress, 1993). Armadillos Dasypus novemcinctus are invasive to Florida (Schmitz \& Brown, 1994) and are predators on marine turtle nests, often causing severe damage (Drennen et al., 1989; Bain et al., 1997). Besides direct predation, raccoons and armadillos also expose nests to the elements, and to predation by crabs, birds and other mammals. Predation threatens many rare species (Hecht \& Nickerson, 1999), with the deleterious impacts of predation losses compounded by habitat loss (Reynolds \& Tapper, 1996). Both problems apply to marine turtle nesting in Florida, making human intervention necessary to ensure turtle reproduction. Reduction of nest predator populations has been widely recommended (Bain et al., 1997; Mroziak et al., 2000), and widely-practised, to protect marine turtle nests (Stancyk, 1982; USFWS/NMFS, 1991; USFWS, 2000; Engeman et al., 2003).

Two adjacent properties on Jupiter Island along Florida's east coast, Hobe Sound National Wildlife Refuge and Saint Lucie Inlet Preserve State Park, provide undeveloped and protected beach habitat for nesting by loggerhead Caretta caretta, leatherback Dermochelys coriacea and green Chelonia mydas turtles, each of which is federally listed as threatened (loggerhead) or endangered (leatherback and green) by the US Fish and Wildlife Service (USFWS, 1994) and categorized on the IUCN Red list as Endangered (loggerhead and green) or Critically Endangered (leatherback; IUCN, 2004). Prior to managing predators, up to $95 \%$ of turtle nests 
were depredated each year (Bain et al., 1997). Consequently, predator removal was identified as the most important management programme (Bain et al., 1997; USFWS, 2000). During the 2000 nesting season an experimental passive tracking index was implemented at the Refuge to monitor turtle nest predators prior to, and in conjunction with, turtle nesting and predator removal. A sharp decline in nest predation to $27.7 \%$ resulted from integrating predator monitoring with predator removal (Engeman et al., 2003).

In 2002 we conducted research to enhance those results by improving the monitoring methodology for armadillos while maintaining high sensitivity for raccoons. We were also interested to find out if previously observed patterns of predator behaviour towards nesting turtles were consistent from year to year (Engeman et al., 2003). Understanding spatial and temporal patterns of predator movement onto the beach in response to turtle nesting facilitates the implementation of removal strategies during nesting, and the development of efficient strategies to manage depredating species before damage begins.

\section{Study area}

The beach is located on the northern portion of Jupiter Island $\left(27^{\circ} 12^{\prime} \mathrm{N}, 80^{\circ} 6^{\prime} \mathrm{W}\right)$, a narrow, $27 \mathrm{~km}$-long barrier island. The Hobe Sound National Wildlife Refuge occupies 298 ha and protects a $5.3 \mathrm{~km}$ segment of the beach (USFWS, 1996), which varies in slope and width, but has a well-defined dune line. The Saint Lucie Inlet Preserve State Park protects the $4.3 \mathrm{~km}$ of beach extending north from the Refuge to the St. Lucie Inlet between Jupiter and Hutchinson Islands, and comprises the northern 416 ha of Jupiter Island, a wider portion of the island with $40 \%$ more terrestrial habitat than the Refuge. However, the beach along the Park narrows substantially as it approaches St. Lucie Inlet, providing less turtle nesting habitat and having lower nest densities than the Refuge portion. The adjoining Refuge and Park beach is open to the public during daylight hours, but accessible only by boat, or by foot from the southern boundary of the Refuge. Because beach width could influence nest predator search efforts, we measured the distance from the dune line to the water's edge at a series of predator monitoring locations (described below). Although variable with the tides, this measurement provides a comparative beach-width index between the two properties.

\section{Methods}

\section{Predator monitoring}

Passive tracking index methodology, valuable for monitoring raccoons since 2000, was the standard for comparison in evaluating a potential design improvement (Engeman et al., 2003). Those tracking plots were placed along the base of the dune vegetation above the high tide line, because this was identified as a travel route for many mammals along the beach (Engeman et al., 2003). Plots were $2 * 3 \mathrm{~m}$, discreetly marked by wooden stakes in 2 corners to avoid detection by animals or interference by humans, and smoothed to produce a good tracking base. Unlike other mammalian wildlife along the beach, armadillos do not adhere strongly to the dune line as a travel route. Their tracks often wander in a nonlinear fashion anywhere from the dunes to the water's edge. Therefore, another tracking index was based on plots formed as 2-m wide strip transects from the dune line to the water's edge. To compare methods, the strips were placed at the same locations along the beach as the dune line plots, with the dune line plots forming the first $3 \mathrm{~m}$ of the strips.

Beginning at a random starting point within $160 \mathrm{~m}$ of the Refuge's southern boundary, plots/strips were randomly placed 160-170 $\mathrm{m}$ apart. The Refuge beach segment had 32 plot/strip locations and the Park had 25, all recorded using a Global Positioning System. The same tracking plots/strips were observed at each assessment period to maximize index comparability across time (Engeman et al., 2003; Ryan \& Heywood, 2003).

The number of track sets (number of intrusions in each plot/strip) by raccoons and armadillos was recorded. The number of intrusions provides superior sensitivity over presence/absence measures (Allen et al., 1996; Engeman et al., 2000). To compare sensitivities for detecting animals on the beach, we recorded data separately for the original dune line plot design and for the additional distance of the strip transects extending beyond those plots to the water's edge (strip extensions). Because the strip transect for indexing purposes includes the dune line plots, the sum of the data from the dune line plot and the strip extension comprises the total information for a strip transect.

The beach substrate made an excellent tracking surface for identifying species and distinguishing the number of intrusions. After 24 hours the plots/strips were examined for spoor and resurfaced (tracks erased and surface smoothed) for the second of two consecutive days of observations. Fair weather conditions prevailed during each of the assessments.

\section{Index calculations}

The index calculation methods as described by Engeman et al. (2003) are applicable to the data from both the dune line plots and the complete strip transects. The index values from the two tracking surfaces are not directly comparable other than for time trends, because of the differences in tracking surface area. To summarize the 
calculation procedures, the number of sets of tracks found on the $i^{\text {th }}$ plot (or strip) on the $j^{\text {th }}$ day, $x_{i j}$, is represented as a linear model $x_{i j}=\mu+P_{i}+D_{j}+\mathrm{e}_{\mathrm{ij}}$, where the term $\mu$ is the overall mean number of sets of tracks per plot (or strip) per day for the area being assessed. $D_{j}$ is a random effect because of the day on which an observation was made, with $j=1$ or 2 in our case. $P_{i}$ is a random effect because of the $i^{\text {th }}$ plot (or strip) with $I=1,2,3 \ldots p_{j}$ representing the number of plots (or strips) contributing data on the $j^{\text {th }}$ day (the number of plots/strips contributing data for the calculations can differ between days if one or more plots are obliterated by humans or the elements). The $e_{i j}$ represent random error associated with each plot/strip each day.

The calculation formula for a passive tracking index (PTI) was defined as (Engeman et al., 2003):

$$
P T I=\frac{1}{2} \sum_{j=1}^{2} \frac{1}{p_{j}} \sum_{i=1}^{p_{j}} x_{i j} .
$$

and the PTI variance estimate was calculated according to:

$$
\operatorname{var}(P T I)=\frac{\sigma_{p}^{2}}{2} \sum_{j=1}^{2} \frac{1}{p_{j}}+\frac{\sigma_{d}^{2}}{2}+\frac{\sigma_{e}^{2}}{2^{2}} \sum_{j=1}^{2} \frac{1}{p_{j}}
$$

where the $\sigma_{p}^{2}, \sigma_{d}^{2}$, and $\sigma_{e}^{2}$ are, respectively, the variance components (Searle et al., 1992) for plot-to-plot (stripto-strip) variability, daily variability and random observational variability, respectively, associated with each plot/strip each day. These variance components were calculated using SAS PROC VARCOMP, with a restricted maximum likelihood estimation procedure (SAS Institute, 1996).

\section{Assessment timing}

We carried out predator indexing in late March (earliest nesting), early May (rapid increase in nesting, some predation), mid-May (heavy nesting, increasing raccoon predation expected), early June (heavy nesting, high predation), late June (heavy nesting, large accumulation of nests, high predation), mid-July (heavy nesting, large accumulation of nests, increasing armadillo predation), and late July (nesting slowing, large accumulation of nests, heavy predation). We also calculated indices for subsets of four plots at the north and south extremities of each property to examine time trends for predator invasion patterns along the beach.

\section{Predator removal methods}

A comprehensive Environmental Assessment identified lethal predator removal as the only practical and legal approach for reducing nest predation (USFWS, 2000). Raccoons and armadillos are primarily nocturnal, and removal efforts were conducted at night (during property closures), which also minimized the potential for human interference. Raccoons were captured in live traps and euthanized. Approximately half of the raccoons and all armadillos were removed from the beach using a .22 cal rifle equipped with a noise suppressor and night vision equipment to maximize hunting success while minimizing disturbance. The timing and location of removal efforts were determined by predator monitoring and observed predation.

\section{Monitoring turtle nesting activity}

All marine turtle nests were counted the morning after deposition. All green and leatherback turtle nests were marked for monitoring reproductive success. Nearly $90 \%$ of nests are by loggerhead turtles, logistically allowing every eighth loggerhead turtle nest to be marked for monitoring at the Refuge, and every third nest in the lower nest density at the Park. A $120 \mathrm{~cm}$-long stake placed on the north-south axis $60 \mathrm{~cm}$ from the clutch, and two $60 \mathrm{~cm}$-long stakes placed $60 \mathrm{~cm}$ east and west of the clutch were labeled with observation date, location and turtle species, and joined by surveyor's tape. Marked nests were monitored daily for depredation, hatchling emergence, tidal overwash, erosion, or other disturbance. Three days after the first observed hatchling emergence, marked nests were excavated to determine reproductive success. Nests exhibiting no signs of hatchling emergence were excavated after 70 days for loggerhead and green turtles, and 80 days for leatherback turtles. The numbers of hatched eggs, unhatched eggs, live and dead hatchlings, and live and dead embryos in pipped eggs were recorded. All live hatchlings were handled and released in accordance with Florida's Sea Turtle Conservation Guidelines (Florida Fish and Wildlife Conservation Commission, 2002). Mean clutch size, hatching success (percent of eggs that hatched), and emerging success (percent of eggs producing hatchlings that emerged from the nest) were calculated for the marked nests that were not depredated, or otherwise destroyed.

\section{Estimation of hatchlings lost to predation}

We estimated the number of hatchlings lost to predation in 2002, and also as if past predation rates from previous landmark years had occurred in 2002 for the Refuge. The past predation rates of particular interest were: 2000, when predator control was first optimized by predator monitoring; 1999, as the only year of intensive contracted predator control without predator monitoring; 1998, as the last year when control was not contracted to professionals; the historical high predation rate of $95 \%$. 
The same historical information was not available for the Park.

We used the 2002 data on the number of nests for each turtle species, the average clutch size for each species, the emergence rate for each species from nests that were not destroyed by predators, the rates at which nests of each species were destroyed by means other than predation, and the predation rates on nests of each species from the above landmark years to predict the number of hatchlings that would have been lost had the above predation rate scenarios occurred in 2002. These calculations can be summarized as (Engeman et al., 2003): $L_{i j}=N_{i} * C_{i} * E_{i} *\left(1-D_{i}\right) * P_{i j}$, where $L_{i j}=$ the number of hatchlings of the $i^{\text {th }}$ species predicted lost in 2002 to predation given the predation rate on the $i^{\text {th }}$ species' nests under the $j^{\text {th }}$ predation rate, $N_{i}=$ number of nests for the $i^{\text {th }}$ species in 2002, $C_{i}=$ the average clutch size for the $i^{\text {th }}$ species in 2002, $D_{i}=$ the proportion of nests destroyed by means other than predation, $E_{i}=$ emergence rate for $i^{\text {th }}$ species in 2002, $P_{i j}=$ the predation rate on the $i^{\text {th }}$ species' nests under the $j^{\text {th }}$ predator removal condition, $i=$ loggerhead, green, or leatherback turtle, $j=$ predation rates for control regimens in place for 2002, $2000,1999,1998$, and for no predator removal (historical high predation).

\section{Results}

\section{Tracking surface designs}

The ability to detect a species is essential to indexing that species. At the Refuge a higher percentage of original dune line plots recorded raccoon tracks than did the strip extensions on four of the seven indexing occasions. On two indexing occasions the same percentage recorded tracks, and on only one indexing occasion did a higher proportion of strip extensions record raccoon tracks than the original plots. The trend for the dune line plots to more frequently have tracks was more pronounced at the Park, where the dune line plots had a higher frequency than the strip extensions for recording raccoon tracks on each of the seven monitoring occasions.

The armadillo results at the Refuge were the mirror image of the raccoon results. On four of seven indexing occasions the strip extensions had a higher proportion of plots recording armadillo tracks than the original plots. On the other three occasions the strip extensions and original plots had the same percentage of plots recording armadillo tracks. At the Park a higher proportion of the strip extensions recorded armadillo tracks on the same four indexing occasions as at the Refuge. On two occasions more original plots recorded armadillo tracks than strip extensions, and the two surfaces were tied once.

\section{Index results}

The addition of the strip extensions to the original plots greatly affected the value of the calculated index, except for raccoons at the Refuge (Table 1). Even though the frequency of tracking by raccoons was higher on the dune line plots than on the strip extensions at the Park, the inclusion of strip extension data into the index calculations for the Park resulted in much higher index

Table 1 Passive tracking index (PTI) values calculated for raccoon and armadillo from two tracking surfaces at Hobe Sound National Wildlife Refuge and Saint Lucie Inlet Preserve State Park, Florida. Dune line plots observe the number of track intrusions to $2 * 3 \mathrm{~m}$ plots, and strip transect plots observe the number of track intrusions to $2 \mathrm{~m}$ wide strip transects from the dune line (including the dune line plots) to the water.

\begin{tabular}{|c|c|c|c|c|}
\hline \multirow[b]{2}{*}{ Timing } & \multicolumn{2}{|c|}{ PTI (variances) for raccoon } & \multicolumn{2}{|c|}{ PTI (variances) for armadillo } \\
\hline & Dune line plot & Total strip transect & Dune line plot & Total strip transect \\
\hline \multicolumn{5}{|c|}{ Hobe Sound National Wildlife Refuge } \\
\hline Late March & $0.000(0.000)$ & $0.000(0.000)$ & $0.000(0.000)$ & $0.016(0.002)$ \\
\hline Early May & $0.083(0.002)$ & $0.250(0.035)$ & $0.000(0.000)$ & $0.000(0.000)$ \\
\hline Mid May & $0.094(0.004)$ & $0.094(0.004)$ & $0.047(0.003)$ & $0.094(0.009)$ \\
\hline Early June & $0.047(0.002)$ & $0.047(0.002)$ & $0.000(0.000)$ & $0.016(<0.001)$ \\
\hline Late June & $0.031(0.001)$ & $0.031(0.001)$ & $0.016(<0.001)$ & $0.047(0.001)$ \\
\hline Mid July & $0.016(<0.001)$ & $0.031(<0.001)$ & $0.047(0.002)$ & $0.125(0.002)$ \\
\hline Late July & $0.188(0.006)$ & $0.219(0.007)$ & $0.031(<0.001)$ & $0.078(0.002)$ \\
\hline \multicolumn{5}{|c|}{ Saint Lucie Inlet Preserve State Park } \\
\hline Late March & $0.320(0.049)$ & $0.700(0.155)$ & $0.000(0.000)$ & $0.000(0.000)$ \\
\hline Early May & $0.060(0.002)$ & $0.340(0.032)$ & $0.000(0.000)$ & $0.040(0.002$ \\
\hline Mid May & $0.720(0.078)$ & $1.220(0.394)$ & $0.020(<0.001)$ & $0.020(<0.001)$ \\
\hline Early June & $0.300(0.027)$ & $0.400(0.042)$ & $0.060(0.001)$ & $0.080(0.002)$ \\
\hline Late June & $0.140(0.003)$ & $0.180(0.005)$ & $0.020(<0.001)$ & $0.100(0.003)$ \\
\hline Mid July & $0.080(0.002)$ & $0.080(0.002)$ & $0.060(0.001)$ & $0.280(0.007)$ \\
\hline Late July & $0.120(0.006)$ & $0.140(0.010)$ & $0.140(0.010)$ & $0.240(0.017)$ \\
\hline
\end{tabular}


Table 2 Deposition of turtle nests over time during 2002 nesting at Hobe Sound National Wildlife Refuge (HSNWR) and Saint Lucie Inlet Preserve State Park (SLIPSP), Florida.

\begin{tabular}{|c|c|c|c|c|c|c|c|c|}
\hline \multirow[b]{2}{*}{ Month } & \multicolumn{2}{|c|}{ Loggerhead } & \multicolumn{2}{|l|}{ Green } & \multicolumn{2}{|c|}{ Leatherback } & \multicolumn{2}{|l|}{ Total } \\
\hline & HSNWR & SLIPSP & HSNWR & SLIPSP & HSNWR & SLIPSP & HSNWR & SLIPSP \\
\hline March & 0 & 0 & 0 & 0 & 2 & 1 & 2 & 1 \\
\hline April & 17 & 5 & 0 & 0 & 13 & 7 & 30 & 12 \\
\hline May & 312 & 87 & 2 & 1 & 13 & 7 & 327 & 95 \\
\hline June & 401 & 117 & 46 & 10 & 4 & 5 & 451 & 132 \\
\hline July & 286 & 66 & 63 & 16 & 1 & 0 & 350 & 76 \\
\hline August & 46 & 12 & 27 & 8 & 0 & 0 & 73 & 20 \\
\hline September & 0 & 0 & 5 & 0 & 0 & 0 & 5 & 0 \\
\hline Total & 1,062 & 287 & 143 & 35 & 33 & 20 & 1,238 & 342 \\
\hline
\end{tabular}

values than obtained strictly from the original dune line plots.

Addition of the strip extensions to the original plots was uniformly beneficial for sensitivity at both properties when monitoring armadillos (Table 1). Addition of the strip extensions reduced the number of zero index values from 3 to 1 for the Refuge, and from 2 to 1 for the Park. Therefore, we used the strip transect index incorporating the combined data from the dune line and strip extension tracking surfaces for all analyses of predator activity during 2002. However, to compare predator activity across the 2002 nesting season at the Refuge with the results reported from 2000 (Engeman et al., 2003) we used the original plot because this was the method used in 2000.

\section{Predator activity and removal}

The Park strip transect index values for raccoons were higher than for the Refuge on all but the final monitoring occasion (Table 1). Armadillo activity was also higher at the Park than at the Refuge at five of the seven assessment periods (Table 1). Both results probably reflect the greater terrestrial wildlife habitat available in the Park.

As in 2000 (Engeman et al., 2003), raccoon activity at the Refuge was heaviest on the northern end of the refuge at the start of the nesting season. Correspondingly, raccoon activity was heavy early in the nesting season on the Park's south side (adjacent to the Refuge). Unlike 2000, beach reinvasion from the south of the Refuge was not indicated. The Park's northern end (the island's northern tip) received its heaviest activity later in the nesting season. Raccoon activity throughout both properties declined during June (Table 1), probably because of initiation of removal efforts in mid May in response to the increased raccoon activity by that time. Ten raccoons and 2 armadillos were removed from the Refuge from mid May to June, and the same numbers were removed from Park. Nevertheless, raccoons were active on the beach throughout the nesting/incubation season (Table 1).
As in 2000 (Engeman et al., 2003), armadillo activity showed its major increase at the Refuge after the initial increase in raccoon activity (Table 2). The same was true at the Park. Armadillo activity appeared spatially associated with saw-palmetto Serenoa repens cover behind the dunes, allowing efficiently focused hunting. A total of 11 raccoons and seven armadillos were removed from the Refuge during turtle nesting, and 17 raccoons and eight armadillos at the Park.

\section{Turtle nesting and predation rates}

Nesting and predation at the Refuge followed trends observed in 2000 (Engeman et al., 2003). Leatherback turtles nested earliest, but with few nests. Loggerhead turtles followed, nesting en masse from late May to early July. Green turtles nested slightly later, overlapping considerably with loggerhead turtles, with peak nest deposition from late June to late July (Table 2).

Nest deposition in 2002 at the Refuge was 21\% lower than during 2000, with 1,238 nests deposited, versus 1,568 in 2000 . Monthly nest predation by each predator species at each property is given in Table 3 , and overall predation rates are included in Table 4 . The most striking reproductive parameter (Table 4) was that overall nest predation for raccoons and armadillos at the Refuge was only $9.4 \%$, the lowest ever recorded. The previous low was 27.7\%, reported in 2000 (Engeman et al., 2003). No nests at the Refuge or the Park were predated within a day of deposition. Predated nests survived an average of 36 days prior to predation at the Refuge and 27 days at the Park. Thus, nests were predated after the elements had erased visual clues to their locations.

Unexpectedly, green turtle nests had much higher depredation rates (Fisher's exact test $\mathrm{P}=0.0003$ for the Refuge, $\mathrm{P}<0.0001$ for the Park) than either loggerhead or leatherback turtles on both properties (Table 4). Low predation rates for leatherback nests were not surprising, because they nest first of the three species, in deeper nests, in lower numbers, and before predators are 
Table 3 Predation on three species of marine turtle nests by raccoons and armadillos over time during 2002 nesting at Hobe Sound National Wildlife Refuge and Saint Lucie Inlet Preserve State Park, Florida.

\begin{tabular}{|c|c|c|c|c|c|c|c|c|c|c|c|c|c|}
\hline \multirow[b]{2}{*}{ Month } & \multicolumn{3}{|c|}{ Loggerhead } & \multicolumn{3}{|c|}{ Green } & \multicolumn{3}{|c|}{ Leatherback } & \multicolumn{4}{|c|}{ All turtles } \\
\hline & A & $\mathrm{R}$ & B & A & $\mathrm{R}$ & B & A & $\mathrm{R}$ & B & A & $\mathrm{R}$ & B & $\mathrm{C}$ \\
\hline \multicolumn{14}{|c|}{ Hobe Sound National Wildlife Refuge } \\
\hline Mar. & 0 & 0 & 0 & 0 & 0 & 0 & 0 & 0 & 0 & 0 & 0 & 0 & 0 \\
\hline Apr. & 0 & 0 & 0 & 0 & 0 & 0 & 0 & 0 & 0 & 0 & 0 & 0 & 0 \\
\hline May & 0 & 0 & 0 & 0 & 0 & 0 & 0 & 0 & 0 & 0 & 0 & 0 & 0 \\
\hline Jun. & 0 & 0 & 0 & 0 & 0 & 0 & 0 & 0 & 0 & 0 & 0 & 0 & 0 \\
\hline Jul. & 4 & 1 & 0 & 1 & 0 & 0 & 0 & 0 & 0 & 5 & 1 & 0 & 6 \\
\hline Aug. & 2 & 1 & 0 & 7 & 6 & 0 & 0 & 0 & 0 & 9 & 7 & 0 & 16 \\
\hline Sep. & 0 & 0 & 0 & 3 & 4 & 0 & 0 & 0 & 0 & 3 & 4 & 0 & 7 \\
\hline Total & 6 & 2 & 0 & 11 & 10 & 0 & 0 & 0 & 0 & 17 & 12 & 0 & 29 \\
\hline \multicolumn{14}{|c|}{ Saint Lucie Inlet Preserve State Park } \\
\hline Mar. & 0 & 0 & 0 & 0 & 0 & 0 & 0 & 0 & 0 & 0 & 0 & 0 & 0 \\
\hline Apr. & 0 & 0 & 0 & 0 & 0 & 0 & 0 & 0 & 0 & 0 & 0 & 0 & 0 \\
\hline May & 0 & 1 & 0 & 0 & 0 & 0 & 0 & 0 & 0 & 0 & 1 & 0 & 1 \\
\hline Jun. & 2 & 9 & 2 & 1 & 0 & 0 & 1 & 0 & 0 & 4 & 9 & 2 & 15 \\
\hline Jul. & 8 & 10 & 0 & 7 & 2 & 0 & 2 & 0 & 0 & 15 & 12 & 0 & 27 \\
\hline Aug. & 9 & 9 & 0 & 3 & 7 & 1 & 0 & 0 & 0 & 14 & 16 & 1 & 30 \\
\hline Sep. & 0 & 2 & 0 & 11 & 1 & 0 & 0 & 0 & 0 & 4 & 3 & 0 & 7 \\
\hline Total & 19 & 31 & 2 & 15 & 10 & 1 & 3 & 0 & 0 & 37 & 41 & 3 & 81 \\
\hline
\end{tabular}

A, armadillo predation; R, raccoon predation; B, both armadillo and raccoon were in nest, but the species initiating predation could not be determined; C, combined predation

Table 42002 reproductive parameters and nest predation rates by raccoons and armadillos for three species of marine turtles nesting at Hobe Sound National Wildlife Refuge (HSNWR) and Saint Lucie Inlet Preserve State Park (SLIPSP), Florida.

\begin{tabular}{|c|c|c|c|c|}
\hline Reproductive parameter & Loggerhead & Green & Leatherback & Total \\
\hline \multicolumn{5}{|c|}{ Hobe Sound National Wildlife Refuge } \\
\hline Number of nests & 1,062 & 143 & 33 & 1,238 \\
\hline Number marked & 132 & 142 & 33 & 307 \\
\hline Predated rate ${ }^{1}(\%)$ & 6.1 & 14.8 & 0 & 9.4 \\
\hline Otherwise destroyed ${ }^{2}(\%)$ & 8.3 & 3.5 & 6.1 & 5.9 \\
\hline Mean clutch size & 103.8 & 117.3 & 71.7 & 106.0 \\
\hline Hatching rate ro $^{3} \%$ & 66.2 & 74.9 & 56.8 & 68.8 \\
\hline Emergence rate $\%$ & 64.9 & 73.6 & 53.4 & 67.3 \\
\hline \multicolumn{5}{|c|}{ Saint Lucie Inlet Preserve State Park } \\
\hline Number of nests & 287 & 35 & 20 & 342 \\
\hline Number marked & 97 & 35 & 20 & 152 \\
\hline Number predated & 52 & 26 & 3 & 81 \\
\hline Predated rate (\%) & 53.6 & 74.3 & 15.0 & 53.3 \\
\hline Otherwise destroyed ${ }^{2}(\%)$ & 4.1 & 2.9 & 5.0 & 3.9 \\
\hline Mean clutch size & 104.1 & 110.0 & 66.0 & 95.9 \\
\hline Hatching rate r $\left.^{3} \%\right)$ & 69.1 & 87.6 & 56.9 & 68.3 \\
\hline Emergence rate $^{3}(\%)$ & 67.4 & 86.5 & 51.6 & 65.8 \\
\hline
\end{tabular}

${ }^{1}$ Excludes two nests predated by bobcats

${ }^{2}$ Nests destroyed by causes other than predation, primarily washing out due to tidal and wave action

${ }^{3}$ Excludes predated and washed out nests

conditioned to the presence of turtle nests on the beach (Tables 2 \& 3). Green turtle nests were much less common than loggerhead nests (Table 2), buried deeper on average (76.1 vs $57.2 \mathrm{~cm})$, and incubated for a slightly shorter time (55.0 vs 57.4 days). We therefore expected green turtle nest depredation to be less than for loggerhead turtles. Possibly predators are well conditioned to seeking turtle nests by the time green turtle eggs have been deposited. Nest predation was delayed at the Refuge until July and peaked in July at the Park (Table 3), during the highest rate of green turtle nest deposition.

The first-ever observation of bobcat Felis rufus as a primary turtle nest predator was made in 2001 (C. Crady, pers. obs.), and bobcat predation destroyed two more 
nests in 2002. Bobcats were not considered for removal because few nests were taken and their presence was considered a deterrent to raccoons and armadillos.

\section{Beach dimensions}

The Refuge had approximately twice the beach area (9.01 ha) of the Park (4.86 ha), and averaged 233.6 turtle nests $\mathrm{km}^{-1}$, and 137.4 nests ha ${ }^{-1}$, versus 79.5 nests $\mathrm{km}^{-1}$ and 70.4 nests ha ${ }^{-1}$ at the Park. The Refuge beach width averaged $17.0 \mathrm{~m}, 50 \%$ wider than the Park portion at $11.3 \mathrm{~m}$. Considering that predation on this beach did not occur when visual clues would lead predators to nests implies that nests requiring less search effort are more vulnerable to predation. The high tide line restricts nesting to a narrow band through much of the Park. This combined with more terrestrial predator habitat, and possibly more predators, probably increases the likelihood that a nest at the Park would be discovered and depredated, even though nest density was lower than at the Refuge.

\section{Estimation of hatchling losses to nest predation}

The predicted number of hatchlings lost to nest predation reinforces the improvements in 2002 over previous years (Table 5). The initial season (2000) at the Refuge of predator removal optimized by monitoring reduced nest predation to $27.7 \%$ from $41.6 \%$ the previous year, when intensive predator removal was applied without monitoring (Engeman et al., 2003). Following 2 additional years of optimized predator removal, predation at the Refuge dropped to the lowest recorded level at 9.4\%. For the 2002 nesting season this represents 16,756 more hatchlings than would have resulted from the predation rate in the initial year (2000) of optimized predator removal, 26,230 more hatchlings than the predation rate in the year (1999) of intensive control without predator monitoring, 32,793 more hatchlings than the last year (1998) predator removal was not contracted to professionals, and 69,004 more than the predation rate at historical highs. Similar comparisons were not feasible for the Park as the present data represent the first year where optimized predator removal was implemented in conjunction with the commencement of turtle nesting, and for which we have complete predator monitoring data and complete turtle nesting data.

\section{Discussion}

We have improved, but kept simple, a method for monitoring predators that is sensitive to both raccoons and armadillos. Integrating the method into predator management activities improved the protection of turtle nests from predation. Probably the most important outcome is the demonstration that predation at a beach historically suffering nearly complete losses of marine turtle nests can have nest predation reduced to nominal levels. The reduction in nest predation to $27.7 \%$ in 2000 was a landmark success for the Refuge. The further reduction to $9.4 \%$ in 2002 is a result not believed achievable (R. Noel, former Refuge Manager, \& M. Stahl, current Refuge Manager, pers. comms.).

Nest predation usually begins at the Refuge in late April/early May (Ecological Associates, unpubl. data; Engeman et al., 2003), with predator activity increasing sharply once turtles are nesting en masse. Predation escalates with continued predator movement to the beach, and as they improve their proficiency at nest location and excavation. However, in 2002, initiation of predator removal in mid May in response to increased predator activity delayed onset of predation until July, partially accounting for the overall low predation.

Turtle nest densities fluctuate annually, with 1,560 nests in 2000 well above average for the Refuge (Engeman et al., 2003). Speculation that reducing 2000 nest depredation to $<28 \%$ was because of the number of nests overwhelming the number of predators is refuted by the 2002 data, where predation on $21 \%$ fewer nests was reduced to $9.4 \%$. Reduced predation on loggerhead nests at the Refuge to only $6.1 \%$ (Table 4 ) is particularly noteworthy because the refuge is in one of Florida's most important marine turtle nesting areas (Meylan et al., 1995), and in the center of US loggerhead turtle nesting activity.

Table 5 The predicted number of potential hatchlings lost to raccoon and armadillo predation at Hobe Sound National Wildlife Refuge, Florida assuming the observed predation rates on three species of sea turtle for 2002, 2000, 1999, 1998 and historical levels of predation $(95 \%)$. Predation rates used in the calculations are given in parenthesis.

\begin{tabular}{lcrrr}
\hline Year providing predation rates & Loggerhead & Green & Leatherback & Total \\
\hline 2002 & $4,002(6.1 \%)$ & $1,763(14.8 \%)$ & $0(0 \%)$ & 5,765 \\
2000 & $19,222(29.3 \%)$ & $3,002(25.2 \%)$ & $297(25.0 \%)$ & 22,521 \\
1999 & $29,719(45.3 \%)$ & $1,989(16.7 \%)$ & $287(24.2 \%)$ & 31,995 \\
1998 & $32,671(49.8 \%)$ & $5,516(46.3 \%)$ & $371(31.3 \%)$ & 38,558 \\
Historical high & $62,325(95.0 \%)$ & $11,317(95.0 \%)$ & $1,127(95.0 \%)$ & 74,769 \\
\hline
\end{tabular}


This study establishes the 2002 results as a baseline for future predator monitoring at the Park. Although the Park's beach segment is not as productive for turtle nesting as the Refuge, hundreds of nests are still deposited there. More predator habitat and greater predation rates makes predator monitoring at the Park valuable for discerning predator activity patterns to optimize their management.

Raccoons can achieve high densities in urban environments (Riley et al., 1998), with the highest observed raccoon density occurring at a park within Fort Lauderdale, Florida (Smith \& Engeman, 2002). The urbanization of coastal Florida raises the possibility that urban raccoons unnaturally increase the levels of nest depredation on beaches adjacent to human development. The Refuge is located immediately to the north of the town of Jupiter Island, which holds a high density of raccoons (pers. obs.). For the 2000 nesting season Engeman et al. (2003) found evidence that after an initial predator removal effort, raccoons reinvaded the Refuge beach from the town. We did not find evidence of this behaviour, indicating that raccoon removal may have resulted in fewer urban juvenile raccoons trained to search for marine turtle nests.

The economics of integrating predator monitoring with predator removal was analysed for the 2000 nesting season by Engeman et al. (2002) and compared to other removal strategies. The success of conservation measures is usually evaluated on the basis of resource improvement, but an economic perspective allows managers to assess the rewards for budgetary expenditures on conservation issues. High benefit-cost ratios were obtained by reducing 2000 nest predation to $27.7 \%$. The further reduction to $<10 \%$ predation at similar costs provided even greater economic returns for management costs in 2002.

\section{Acknowledgements}

K. Fagerstone and J.R. Mason provided valuable reviews of earlier versions of this manuscript.

\section{References}

Allen, L., Engeman, R.M. \& Krupa, H.W. (1996) Evaluation of three relative abundance indices for assessing dingo populations. Wildlife Research, 23,197-206.

Bain, R.E., Jewell, S.D., Schwagerl, J. \& Neely Jr, B.S. (1997) Sea Turtle Nesting and Reproductive Success at the Hobe Sound National Wildlife Refuge (Florida), 1972-1995. Report to US Fish and Wildlife Service, ARM Loxahatchee NWR, USA.

Dickman, C.R. \& Doncaster, C.P. (1987) The ecology of small mammals in urban habitats. I. Populations in patchy environments. Journal of Animal Ecology, 56, 629-640.

Drennen, D., Cooley, D. \& Devore, J.E. (1989) Armadillo predation on loggerhead turtle eggs at two national wildlife refuges in Florida, USA. Marine Turtle Newsletter, 1989, 7-8.
Engeman, R.M., Martin, R.E., Constantin, B., Noel, R. \& Woolard, J. (2003) Monitoring predators to optimize their management for marine turtle nest protection. Biological Conservation, 113,171-178.

Engeman, R.M., Pipas, M.J., Gruver, K.S. \& Allen, L. (2000) Monitoring coyote populations with a passive activity index. Wildlife Research, 27, 553-557.

Engeman, R.M., Shwiff, S.A., Constantin, B., Stahl, M. \& Smith, H.T. (2002) An economic analysis of predator removal approaches for protecting marine turtle nests at Hobe Sound National Wildlife Refuge. Ecological Economics, 42, 469-478.

Florida Fish and Wildlife Conservation Commission (2002) Sea Turtle Conservation Guidelines. Florida Fish and Wildlife Conservation Commission, Tallahassee, USA.

Hecht, A. \& Nickerson, P.R. (1999) The need for predator management in conservation of some vulnerable species. Endangered Species Update, 16, 114-118.

IUCN (2004) IUCN Red List of Threatened Species. IUCN, Gland, Switzerland [http:/ / www.redlist.org, accessed 11 May 2005].

Meylan, A., Schroeder, B. \& Mosier, A. (1995) Sea Turtle Nesting Activity in the State of Florida 1979-1992. Florida Marine Research Publication No. 52, Florida Marine Research Institute, St. Petersburg, USA.

Mroziak, M.L., Salmon, M. \& Rusenko, K. (2000) Do wire cages protect sea turtles from foot traffic and nest predators? Chelonian Conservation Biology, 3, 693-698.

Reynolds, J.C. \& Tapper, S.C. (1996) Control of mammalian predators in game management and conservation. Mammal Review, 26, 127-156.

Riley, S.P.D., Hadidian, J. \& Manski, D.A. (1998) Population density, survival, and rabies in raccoons in an urban national park. Canadian Journal of Zoology, 76, 1153-1164.

Ryan, D.A. \& Heywood, A. (2003) Improving the precision of longitudinal ecological surveys using precisely defined observational units. Environmetrics, 14, 283-293.

SAS Institute (1996) SAS/STAT User's Guide. SAS Institute, Carey, USA.

Schmitz, D.C. \& Brown, T.C. (1994) An Assessment of Invasive Non-Indigenous Species in Florida's Public Lands. Florida Department of Environmental Protection, Tallahassee, USA.

Searle, S.R., Casella, G. \& McCulloch, C.E. (1992) Variance Components. Wiley \& Sons, New York, USA.

Smith, H.T. \& Engeman, R.M. (2002) An extraordinary raccoon density at an urban park in Florida. Canadian Field Naturalist, 116, 636-639.

Stancyk, S.E. (1982) Non-human predators of sea turtles and their control. In Biology and Conservation of Sea Turtles (ed. K.A. Bjorndal), pp. 139-152. Smithsonian Institution Press, Washington, DC, USA.

US Congress (1993) Harmful Non-indigenous Species in the United States. Office of Technology Assessment, OTA-F-565, Government Printing Office, Washington, DC, USA.

USFWS (US Fish and Wildlife Service) (1994) Endangered and Threatened Wildlife and Plants. Federal Register. 50,17.11, 17.12, USA

USFWS (US Fish and Wildlife Service) (1996) Hobe Sound National Wildlife Refuge. Department of Interior/US Fish and Wildlife Service publication, RF 41561, Washington, DC, USA.

USFWS (US Fish and Wildlife Service) (2000) Environmental Assessment for the Management of Predation Losses to Sea Turtle Nests at the Hobe Sound National Wildlife Refuge, Martin County, Florida. US Fish and Wildlife Service, Hobe Sound, USA. 
USFWS/NWFS (US Fish and Wildlife Service/National Marine Fisheries Service) (1991) Recovery Plan for US Population of Loggerhead Turtle. National Marine Fisheries Service, Washington, DC, USA.

Williams-Wall, N.J., O'Hara, J., Gallagher, R.M., Worth, D.F., Peery, B.D. \& Wilcox, J.R. (1983) Spatial and temporal trends of sea turtle nesting on Hutchinson Island, Florida, 1971-1979. Bulletin of Marine Science, 33, 55-66.

\section{Biographical sketches}

Richard Engeman carries out research to develop practical, quantitatively valid wildlife indexing methods, ecological sampling methods, and methods to monetarily value rare species and habitats for use in bioeconomic analyses.

Erik Martin researches the ecology, conservation and management of marine turtle nesting, with an emphasis on collection and analysis of reproductive parameters.

Henry Smith researches the conservation of endangered plant and animal species and the deterrence of invasive species throughout the state parks of southern Florida.

John Woolard carries out operational wildlife management methods and scientific data collection activities.

Carrie Crady surveys marine turtle nesting and associated reproductive parameters

Stephanie Shwiff develops bioeconomic valuations and analyses of the human-wildlife interface, particularly for species in conflict with humans relative to rare species, wildlife disease, or agriculture.

Bernice Constantin focuses on developing strategies and implementing methodologies for the resolution of humanwildlife conflicts using practical, ecologically sound methods.

Margo Stahl focuses on preservation and conservation of habitats and species, with a primary focus on nesting sea turtles.

John Griner likewise focuses on conservation of habitats and species, with a focus on nesting sea turtles. 